\title{
GROWTH OF BYSSOCHLAMYS NIVEA IN PINEAPPLE JUICE UNDER THE EFFECT OF WATER ACTIVITY AND ASCOSPORE AGE
}

\author{
M. Zimmermann ${ }^{1}$, S. Miorelli ${ }^{1}$, P.R. Massaguer ${ }^{2}$, G.M.F. Aragão ${ }^{1 *}$ \\ ${ }^{1}$ Departamento de Engenharia Química e Engenharia de Alimentos, Universidade Federal de \\ Santa Catarina, Florianópolis, SC, Brasil; ${ }^{2}$ Departamento de Processos Químicos, Faculdade de Engenharia Química, \\ Universidade Estadual de Campinas, Campinas, SP, Brasil.
}

Submitted: March 04, 2010; Returned to authors for corrections: June 12, 2010; Approved: August 23, 2010.

\begin{abstract}
The study of thermal resistant mould, including Byssochlamys nivea, is of extreme importance since it has been associated with fruit and fruit products. The aim of this work is to analyze the influence of water activity $\left(\mathrm{a}_{\mathrm{w}}\right)$ and ascospore age $(\mathrm{I})$ on the growth of Byssochlamys nivea in pineapple juice. Mold growth was carried out under different conditions of water activity $\left(\mathrm{a}_{\mathrm{w}}\right)(0.99,0.96,0.95,0.93,0.90)$ and ascospore age (I) $(30,51,60,69,90$ days). Growth parameters as length of adaptation phase $(\lambda)$, maximum specific growth rate $\left(\mu_{\max }\right)$ and maximum diameter reached by the colony $(\mathrm{A})$ were obtained through the fit of the Modified Gompertz model to experimental data (measuring radial colony diameter). Statistica 6.0 was used for statistical analyses (significance level $\alpha=0.05$ ). The results obtained clearly showed that water activity is statistically significant and that it influences all growth parameters, while ascospore age does not have any statistically significant influence on growth parameters. Also, these data showed that by increasing $\mathrm{a}_{\mathrm{w}}$ from 0.90 to 0.99 , the $\lambda$ value substantially decreased, while $\mu_{\max }$ and A values rose. The data contributed for the understanding of the behavior of B. nivea in pineapple juice. Therefore, it provided mathematical models that can well predict growth parameters, also helping on microbiological control and products' shelf life determination.
\end{abstract}

Key words: Byssochlamys nivea, mould growth, pineapple juice, water activity, ascospore age.

\section{INTRODUCTION}

Thermal processing is widely applied in the production of fruit based foods. The increased demand has led the industry to develop technologic processes capable of minimizing the presence of spoilage agents in the final product, preserving organoleptic and nutritional characteristics. The understanding of microbiology and thermal process is essential for ensuring the quality and food safety of these products.

Most molds show very limited heat resistance, having their asexual phase (conidia and hyphaes) easily eliminated after short heating at low temperatures. Some more heat 
resistant species owe their heat resistance to thick walled sexual ascospores, which can survive to thermal processes usually applied in the food production, including the production of fruit juices (23). Ascospores can be activated by the process' temperature, being able to germinate and grow into the package during storage, reducing the product's shelf life and causing economic losses (17). Extremely resistant species such as Byssochlamys nivea, Byssochlamys fulva, Talaromyces flavus and Neosartorya fischeri serve as standards for spore resistance and their absence indicates the quality of sterilization processes (7).

Some species of Byssochlamys, like Byssochlamys nivea, can be considered as potential producers of mycotoxin patulin in post-pasteurization stages $(22,15)$. Patulin is a toxic metabolite that can cause acute symptoms including nervousness, convulsions, lung congestion, edema, hyperemia, gastrointestinal tract distension, intestinal hemorrhage and epithelial cell degeneration (9).

Mold growth is markedly affected by different environmental factors, and one of the most important is water activity $\left(\mathrm{a}_{\mathrm{w}}\right)(10)$. Roland and Beuchat (13) reported that the minimum level of $\mathrm{a}_{\mathrm{w}}$ that allowed $B$. nivea to grow was 0.89 when the temperature was $30^{\circ} \mathrm{C}$.

Spore age is considered the time that the microorganism remains in its dormant state. Sussman and Halvorson (21) defined microorganism dormancy as a hypometabolic state in which the development is delayed. According to Chapman et al. (5), ascospores contaminating fruit products are most likely to come from soil and may be of varying maturities. Slongo et al. (19), studying thermal inactivation of spores of Neosartorya fischeri, found that older ascospores had a higher heat resistance, evidencing the influence of ascospore age on the heat resistance of that microorganism. Little has been published on the effects of ascospore age on the growth of heat resistant mold.

The constant increase of microbial safety and quality concerns have focused a lot of attention onto predictive microbiology, where mathematical modeling can be applied to quantify and predict microbial behavior under different growth conditions. Mathematical models can also be used to determine shelf life and optimum storage conditions (27).

The aim of this work was to analyze the influence of water activity $\left(\mathrm{a}_{\mathrm{w}}\right)$ and ascospore age (I) on the growth of Byssochlamys nivea in pineapple juice.

\section{MATERIAL AND METHODS}

\section{Microorganism and ascospore suspension}

The strain of Byssochlamys nivea used in this work was isolated by Aragão (2) during a research in the Thermobacteriology Laboratory of the State University of Campinas, in Campinas, SP, Brazil.

Cells were pre-cultivated in Potato Dextrose Agar (PDA, Himedia Laboratories, Mumbai, IND) at $30^{\circ} \mathrm{C}$ for seven days. The colonies were flowed with distillated water and scrapped from the surface. Roux bottles containing $180 \mathrm{~mL}$ of Malt Extract Agar (MEA, Difco Laboratories, Detroit, MI, USA) were inoculated with $0.5 \mathrm{~mL}$ of that pre-culture and then these bottles were incubated at $30^{\circ} \mathrm{C}$ to reach different ages $(30,51$, 60, 69 and 90 days). After each desired age, ascospore suspensions were obtained as described by Salomão et al. (14). Ascospores were harvested by flooding the medium surface with $25 \mathrm{~mL}$ sterile distillated water and gently rubbing the ascospores from the surface with a sterile glass rod and glass pearls. The ascospore suspension was filtered through layers of gauze and centrifuged at $2000 \mathrm{~g}$ for 15 minutes. The suspension was washed three times with five milliliters sterile water, followed by centrifugation. The absence of hyphaes was confirmed through microscopy analyses. The final suspension was prepared resuspending the precipitate in a small volume of sterile water and stored under refrigeration at four degrees Celsius for future use.

Ascospore concentration was determined after activation at $80^{\circ} \mathrm{C}$ for 30 minutes followed by appropriate serial dilutions 
in sterile distilled water and then pour plating in PDA added with $50 \mathrm{mg} . \mathrm{L}^{-1}$ Bengal rose and a $100 \mathrm{~g} . \mathrm{L}^{-1}$ tartaric acid solution until $\mathrm{pH} 3.5$ (3). The plates were incubated at $30^{\circ} \mathrm{C}$ for three days and the grown colonies were counted. All experiments were performed in duplicate.

\section{Growth media}

Commercial pineapple juice ( $\mathrm{pH} 3.69$ and $12.3^{\circ}$ Brix) from the same brand and production lot was used for all experiments. Values of $\mathrm{a}_{\mathrm{w}}(0.90,0.93,0.95,0.96$ and 0.99$)$ were adjusted using sucrose and distilled water. Water activity measurements of the adjusted media were determined using an Aqualab (Models Series 3TE, Decagon Devices, Pullman, WA, USA).

\section{Preparation of inoculum}

Experiments were conducted in $250 \mathrm{~mL}$ PET (polyethylene terephthalate) bottles, previously sanitized with a $3 \mathrm{~mL} . \mathrm{L}^{-1}$ peracetic acid aqueous solution (P3 Oxônia Ativo 150, Ecolab, Barueri, SP, Brazil), during 30 minutes. The caps were also sanitized using a $0.5 \mathrm{~mL} . \mathrm{L}^{-1}$ aqueous solution of the same product, during the same contact time. After the contact time, bottle and cap were rinsed twice with sterile distilled water (20).

Pineapple juice was submitted to heat treatment of $110^{\circ} \mathrm{C}$ for 15 minutes, followed by cooling to room temperature. The ascospore suspension was activated at $80^{\circ} \mathrm{C}$ for 30 minutes, and then inoculated into the juice in order to obtain a final concentration of one ascospore. $\mathrm{mL}^{-1}$.

\section{Growth monitoring}

Byssochlamys nivea growth was monitored by measuring the radial growth $[\mathrm{mm}]$ based on the method reported by Peña et al. (11), using a graduated ruler and a flashlight for helping in the visualization.

The inoculated bottles were tilted $45^{\circ}$ to increase the surface area and to facilitate the measurement. Bottles were stored at $30^{\circ} \mathrm{C}$ and all experiments were made in duplicates.

\section{Mathematical modeling}

Modified Gompertz model (Equation 1) was fitted to experimental data, using the software Statistica 6.0.

$$
\ln y=A \exp \left\{-\exp \left\{\left(\frac{\mu \max \times e}{A}\right)(\lambda-t)\right\}+1\right\}
$$

Where:

Colony diameter is $\mathrm{y}[\mathrm{mm}]$ at a given time $\mathrm{t}[\mathrm{h}], \lambda$ is the duration of adaptation phase $[\mathrm{h}] ; \mu_{\max }$ is the maximum specific growth rate $[\mathrm{mm} / \mathrm{h}], \mathrm{A}$ is the maximum diameter reached by the colony $[\mathrm{mm}]$ and $e=2.7182$.

General secondary models (power model presented in Equation 2, and linear model presented in Equation 3) were used to describe the influence of the statistically significant factors on growth parameters, using the Excel software.

$$
\begin{aligned}
& y=a x^{b} \\
& y=a x+b
\end{aligned}
$$

The empirical parameters of the equation were $a$ and $b ; x$ corresponds to values of $\mathrm{a}_{\mathrm{w}}$ or I; and $y$ corresponds to values of $\lambda, \mu_{\max }$ or A obtained from the fit of the Modified Gompertz model to experimental data.

\section{Statistical analyses}

For fit analysis of Modified Gompertz model to experimental data, the statistical parameters Correlation Coefficient $\left(\mathrm{R}^{2}\right)$ and Mean Square Error (MSE) were calculated. Parameters of growth obtained by the mathematical modeling were submitted to analysis of variance (ANOVA) with significance level $\alpha=0.05$, using the software Statistica 6.0.

\section{RESULTS}

Conditions of growth shown in Figures 1 and 2 were chosen randomly. Figure 1 illustrates growth curves of $B$. nivea in pineapple juice when the ascospore age was 30 days and water activity was adjusted at 0.90, 0.93, 0.95, 0.96 and 0.99 . 
The growth curves of $B$. nivea in pineapple juice when $\mathrm{a}_{\mathrm{w}}$ was 0.99 and ascospore age was 30, 51, 60, 69 and 90 days are shown in Figure 2. Figures 1 and 2 also show the fit of the Modified Gompertz model (MG) to experimental data. As it can be seen on these Figures, the Modified Gompertz model is able to describe mold growth in all curves, completing the prediction satisfactorily. It can be observed from Figure 1 that to high water activity values the microorganism growth was faster and the adaptation phase was shorter than in low $\mathrm{a}_{\mathrm{w}}$ values. In fact, all growth parameters were affected, indicating an influence of $\mathrm{a}_{\mathrm{w}}$ on $B$. nivea growth. On the other hand, for $\mathrm{a}_{\mathrm{w}}=0.99$, ascospore age barely showed any effect on the microorganism growth parameters (Figure 2), once growth curves were almost overlapped.

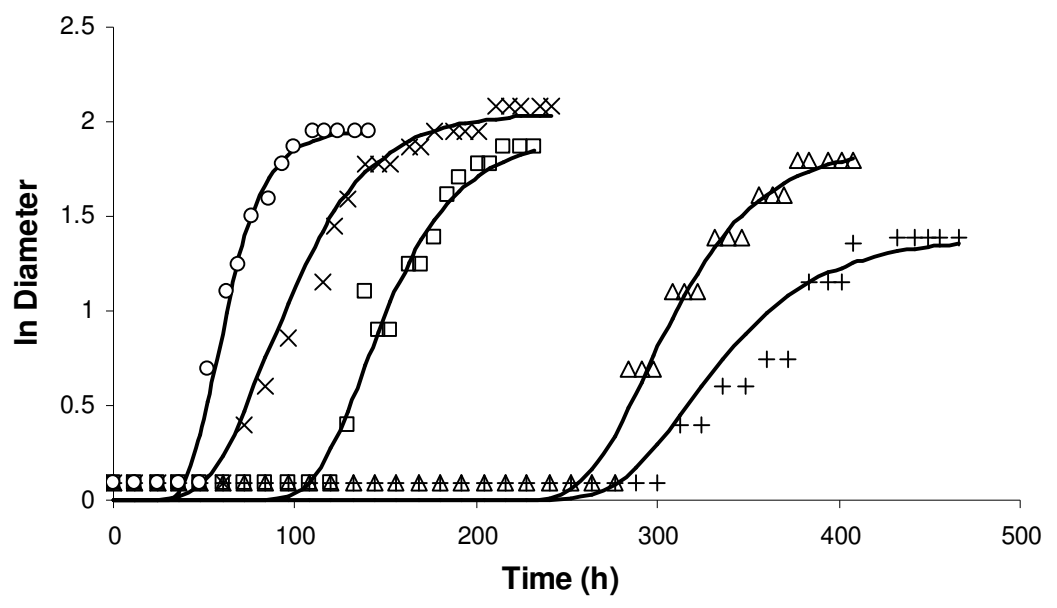

Figure 1. Growth curves of $B$. nivea growth in pineapple juice under the conditions of 30 day ascospore age and water activity adjusted to $(+) 0.90,(\Delta) 0.93,(\square) 0.95,(x) 0.96,(\circ) 0.99$. The continuous line represents the fit of the Modified Gompertz model (MG) to the experimental data.

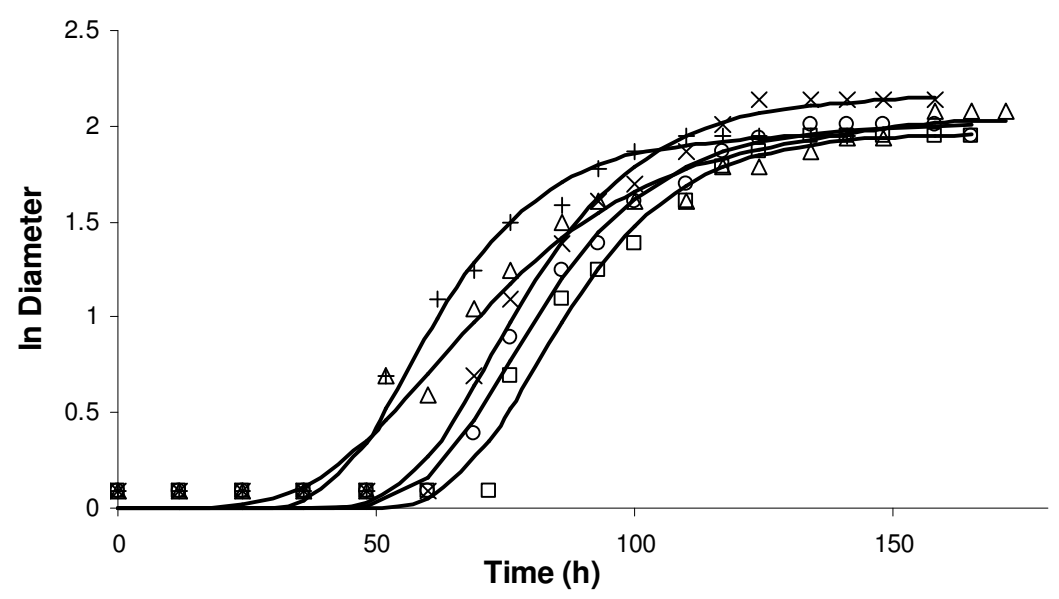

Figure 2. Curves of $B$. nivea growth in pineapple juice under the conditions of water activity adjusted to 0.99 and ascospore age of (+) 30 days, ( $\Delta$ ) 51 days, () 60 days, (x) 69 days, (०) 90 days. The continuous line represents the fit of the Modified Gompertz model (MG) to the experimental data. 
The ascospore age condition of 60 days is used as an example to illustrate the growth parameters $\lambda, \mu_{\max }$, and $\mathrm{A}$ values obtained from the Modified Gompertz model (Table 1). All the other combinations of growth conditions tested showed similar behavior. This Table also shows $\mathrm{R}^{2}$ and MSE statistical parameters for the fit of the model to experimental data. It can be observed the model goodness of fit through presented statistical indices. Analyzing the growth parameter $\lambda$ through these experiments, it can be seen that the increasing of water activity from the lower level to the upper level resulted in a reduction of approximately $350 \%$ in $\lambda$ value.

Values of growth parameters were submitted to an analysis of variance (ANOVA) with significance level of $\alpha=$ 0.05. The results of this statistical analysis are shown on Table 2. It can be noticed that the factor of water activity presented statistically significant influence $(\mathrm{p}<0.05)$ on all growth parameters, in the range of $a_{w}$ studied (values in bold); and the factor of ascospore age did not show statistically significant influence in any growth parameter.

Table 3 presents the average and standard deviation of $\lambda$, $\mu_{\max }$ and $\mathrm{A}$ obtained in each $\mathrm{a}_{\mathrm{w}}$ condition using all ascospore age conditions, once this factor was not statistically significant. Power model was appropriate to describe the mathematical relation between $\mathrm{a}_{\mathrm{w}}$ and growth parameters $\lambda$ (Equation 4) and $\mu_{\max }$ (Equation 5), showing a very good prediction in both cases, with $\mathrm{R}^{2}$ equal to 0.915 and 0.922 , respectively.

$$
\begin{gathered}
\lambda=56.051 a_{w}^{-16.597} \\
\mu_{\max }=0.0503 a_{w}^{8.9105}
\end{gathered}
$$

The mathematical relation between $\mathrm{a}_{\mathrm{w}}$ and $\mathrm{A}$ was linear and is presented on Equation 6, with $\mathrm{R}^{2}=0.727$.

$$
A=41.727 a_{w}-33.561
$$

Table 1. Growth parameter average $\left(\lambda, \mu_{\max }\right.$ and $\left.\mathrm{A}\right)$ for $B$. nivea in pineapple juice, MSE and $\mathrm{R}^{2}$ statistically obtained by fitting the Modified Gompertz model to experimental data when ascospore age condition was 60 days.

\begin{tabular}{ccccccc}
\hline Ascospore Age & $\mathbf{a}_{\mathbf{w}}$ & $\boldsymbol{\lambda} \pm \mathbf{S D}(\mathbf{h})$ & $\boldsymbol{\mu}_{\max } \pm \mathbf{S D}\left(\mathbf{m m} \cdot \mathbf{h}^{-\mathbf{1}}\right)$ & $\mathbf{A} \pm \mathbf{S D}(\mathbf{m m})$ & $\mathbf{M S E}$ & $\mathbf{R}^{\mathbf{2}}$ \\
\hline \multirow{6}{*}{60 days } & 0.90 & $291.64 \pm 19.12$ & $0.021 \pm 0.003$ & $4.88 \pm 0.81$ & 0.030 & 0.983 \\
& 0.93 & $206.77 \pm 18.00$ & $0.024 \pm 0.007$ & $4.40 \pm 0.03$ & 0.030 & 0.942 \\
& 0.95 & $167.47 \pm 1.22$ & $0.029 \pm 0.005$ & $5.10 \pm 0.85$ & 0.037 & 0.990 \\
& 0.96 & $88.31 \pm 10.84$ & $0.039 \pm 0.009$ & $6.80 \pm 0.82$ & 0.058 & 0.993 \\
& 0.99 & $64.80 \pm 0.42$ & $0.046 \pm 0.003$ & $7.14 \pm 0.31$ & 0.058 & 0.993 \\
\hline
\end{tabular}

SD - Standard Deviation

Table 2. Analysis of variance (ANOVA) for growth parameters of $B$. nivea in pineapple juice.

\begin{tabular}{cccc}
\hline \multirow{2}{*}{ Factor } & \multicolumn{3}{c}{ p-value } \\
\cline { 2 - 4 } & $\boldsymbol{\lambda}(\mathbf{h})$ & $\boldsymbol{\mu}_{\max }\left(\mathbf{m m} \cdot \mathbf{h}^{-1}\right)$ & $\mathbf{A}(\mathbf{m m})$ \\
\hline Ascospore Age & 0.140 & 0.832 & 0.487 \\
$\mathbf{a}_{\mathbf{w}}$ & $\mathbf{0 . 0 0 0}$ & $\mathbf{0 . 0 0 0}$ & $\mathbf{0 . 0 0 0}$ \\
\hline
\end{tabular}


Table 3. Average of $\lambda, \mu_{\max }$ and A for all ascospore age conditions in each condition of $\mathrm{a}_{\mathrm{w}}$ studied during growth of $B$. nivea in pineapple juice.

\begin{tabular}{cccc}
\hline $\mathbf{a}_{\mathbf{w}}$ & $\boldsymbol{\lambda} \pm \mathbf{S D}(\mathbf{h})$ & $\boldsymbol{\mu}_{\max } \pm \mathbf{S D}(\mathbf{m m} / \mathbf{h})$ & $\mathbf{A} \pm \mathbf{S D}(\mathbf{m m})$ \\
\hline 0.90 & $285.06 \pm 24.62$ & $0.019 \pm 0.003$ & $3.82 \pm 1.23$ \\
0.93 & $273.33 \pm 46.29$ & $0.020 \pm 0.004$ & $3.49 \pm 1.41$ \\
0.95 & $130.87 \pm 22.22$ & $0.023 \pm 0.006$ & $6.08 \pm 0.66$ \\
0.96 & $65.16 \pm 17.74$ & $0.032 \pm 0.010$ & $6.93 \pm 0.61$ \\
0.99 & $51.60 \pm 11.80$ & $0.044 \pm 0.007$ & $8.37 \pm 1.60$ \\
\hline SD - Standard Deviation
\end{tabular}

SD - Standard Deviation

\section{DISCUSSION}

In this study, the minimum colony diameter identified by naked eye was approximately $2 \mathrm{~mm}$. According to Gibson et al. (8), the minimum size for seeing colonies is $3 \mathrm{~mm}$, which is enough to cause rejection of the product by the consumer. The growth curves based on colony diameters followed the expected microbiologic growth behavior, having an adaptation time associated to the germination of the ascospores, an accelerating period followed by linear growth and an upper asymptote, which are all in agreement with results found by Valík and Piecková (25).

The simplicity of the predictive model is a decisive in defining which model should be applied. The Modified Gompertz model is simple, since it has only three parameters and all of them have physical meaning. Zwietering et al. (26) concluded that the Modified Gompertz model was statistically sufficient to describe microbial growth data. In this study, the Modified Gompertz model showed a good fit to the experimental data as it can be visually observed (Figures 1 and 2). The MSE presented by the fit (Table 2) showed that the model produced a close prediction of the growth data. In addition, $\mathrm{R}^{2}$ shown by the fit was higher than 0.9 in all experiments (Table 2), indicating that most of the variation was explained and the model was adequate to predict the growth of $B$. nivea in pineapple juice.

The importance of the adaptation phase $(\lambda)$ and the maximum specific growth rate $\left(\mu_{\max }\right)$ for the juice industry is related to the identification of the microorganism colony by consumers. Once the adaptation phase is finished, microorganism growth can hardly be controlled and the identification of the colony will be dependent on the maximum specific growth rate. The longer the adaptation phase and the lower the maximum specific growth rate, the better for the industry.

Abellana et al. (1) found that mold growth was fast with water activity adjusted to 0.90 and that it decreased as the water activity decreased. Bouras et al. (4) reported that, even under the most favorable temperature conditions $\left(25^{\circ} \mathrm{C}\right)$, mold growth decreased dramatically when $\mathrm{a}_{\mathrm{w}}$ was reduced from 0.99 to 0.95 . These results are in accordance to the data found in this study, since fast microorganism growth was observed when water activity was at the highest level $\left(\mathrm{a}_{\mathrm{w}}=0.99\right)$, and growth decreased when water activity was at the lowest level $\left(\mathrm{a}_{\mathrm{w}}=0.90\right)$ (Figure 1). Besides, statistical analyses (Table 3) showed a significant influence of water activity on all growth parameters of $B$. nivea in pineapple juice.

There are several studies in the literature that report the influence of ascospore age on thermal inactivation $(24,18)$. Dijksterhuis and Teunissen (6) have also shown that ascospore age affects high pressure inactivation. However, there are no studies that analyze whether ascospore age influences mold growth. In Figure 2, the growth curves almost overlap, although they follow the expected natural growth behavior, 
indicating that ascospore age did not affect the growth of microorganism. The statistical analyses also found no statically significant influence of this factor in any growth parameter of B. nivea (Table 3). As a result, it can be concluded that ascospore age, up to the three months studied in this research, has no influence on the growth of $B$. nivea in pineapple juice.

Secondary models have been developed by adjusting existing equations such as the 'square-root' model (12) or the Arrhenius equation (16) to experimental data. This study has provided secondary models that can adequately predict the growth parameters of $B$. nivea in pineapple juice, taking water activity into account regardless of ascospore age. These models can be applied in the range of $\mathrm{a}_{\mathrm{w}}$ studied.

\section{REFERENCES}

1. Abellana, M.; Magrí, X.; Sanchis, V.; Ramos, A.J. (1999). Water activity and temperature effects on growth of Eurotium amstelodami, E. chevalieri and E. herbariorum on a sponge cake analogue. Int. J. Food Microbiol. 52, 97-103.

2. Aragão, G.M.F. (1989). Identificação e determinação da resistência térmica de fungos filamentosos termo-resistentes isolados de polpa de morango. São Paulo, Brasil, 139p. (M.Sc. Dissertation. Faculdade de Engenharia de Alimentos. UNICAMP).

3. Baglioni, F.; Gumerato, H.F.; Massaguer, P.R. (1999). Ocorrência de fungos filamentosos termo-resistentes em polpa de tomate envasada assepticamente. Ciênc. Tecnol. Aliment. 19 (2), 258-263.

4. Bouras, N.; Kim, Y.M.; Strelkov, S.E. (2009). Influence of water activity and temperature on growth and mycotoxin production by isolates of Pyrenophora tritici-repentis from wheat. Int. J. Food Microbiol. 131, 251-255.

5. Chapman, B.; Winley, E.; Fong, A.S.W.; Hocking, A.D.; Stewart, C.M.; Buckle, K.A. (2007). Ascospore inactivation and germination by high pressure processing is affected by ascospore age. Innovative Food Science and Emerging Technologie. 8, 531-534.

6. Dijksterhuis, J.; Teunissen, P.G.M. (2004). Dormant ascospores of Talaromyces macrosporus are activated to germinate after treatment with ultra high pressure. J. Appl. Microbiol. 96, 162-169.

7. Eicher, R.; Ludwig, H. (2002). Influence of activation and germination on high pressure inactivation of ascospores of the mould Eurotium repens. Comp. Biochem. Physiol.. 131, 595-604.
8. Gibson, A.M.; Baranyi, J.; Pitt, J.I.; Eyles, M.J; Roberts, T.A. (1994). Predicting fungal growth: the effect of water activity on Aspergillus flavus and related species. Int. J. Food Microbiol. 23, 419-431.

9. Mahfoud, R.; Maresca, M.; Garmy, N.; Fantini, J. (2002). The mycotoxin patulin alters the barrier function of the intestinal epithelium: Mechanism of action of the toxin and protective effects of glutathione. Toxicol. Appl. Pharmacol. 181, 209-218.

10. Mazas, M.; Martínez, S.; López, M.; Bernardo-Álvarez, A.; Martín, R. (1999). Thermal inactivation of Bacillus cereus spores affected by the solutes used to control water activity of the heating medium. Int. J. Food Microbiol. 53, 61-67.

11. Peña, W.; Faria, J.A.; Massaguer, P.R. (2004). Development of predictive model on the growth of the spoilage mould, Paecilomyces variotti in pineapple juice. Fruit Processing. 14, 420-426.

12. Ratkowsky, D.A.; Olley, J.; McMeekin, T.A.; Ball, A. (1982). Relationship between temperature and the growth rate of bacterial cultures. J. Bacteriol. 149, 1-5.

13. Roland, J.O.; Beuchat, L.R. (1984). Influence of temperature and water activity on growth and patulin production by Byssohlhamys nivea in apple juice. Appl. Environ. Microbiol.. 47, 205-207.

14. Salomão, B.C.M.; Slongo, A.P.; Aragão, G.M.F. (2007). Heat resistance of Neosartorya fischeri in various juices. LWT - Food Science and Technology. 40, 676-680.

15. Sant'Ana, A.S.; Rosenthal, A.; Massaguer, P.R. (2008). The fate of patulin in apple juice processing: A review. Food Res. Int. 41, 441-453.

16. Schoolfield, R.M.; Sharpe, P.J.M.; Magnuson, C.E. (1981). Non-linear regression of biological temperature dependent rate models based on absolute reaction rate theory. J. Theor. Biol. 88, 719-731.

17. Slongo, A.P.; Aragão, G.M.F. (2006). Factors affecting the thermal activation of Neosartorya fischeri in pineapple and papaya nectars. Braz. J. Microbiol. 37, 266-270.

18. Slongo, A.P.; Aragão, G.M.F. (2008). Behaviour of Neosartorya fischeri ascospores in pineapple juice. Bol. Cent. Pesqui. Process. Aliment. 26, 56.

19. Slongo, A.P.; Miorelli, S.; Aragão, G.M.F. (2005). Influência de diferentes fatores na termorresistência de Neosartorya fischeri em suco de mamão. Alimentos e Nutrição-Araraquara. 16 (4), 377-387.

20. Silva, A.R.; Massaguer, P.R. (2005). Radial growth modelling of Aspergillus niger in mango nectar as a function of $\mathrm{a}_{\mathrm{w}}, \mathrm{pH}$, and temperature in PET package. V Congresso Iberoamericano de Ingenieria de Alimentos, Puerto Vallarta, Jalisco, Mexico.

21. Sussman, S.; Halvorson, H.O. (1966). Spores, their Dormancy and Germination. Harper \& Row, New York, USA.

22. Taniwaki, M.H.; Hocking, A.D.; Pitt, J.I.; Fleet, G.H. (2001). Growth of fungi and mycotoxin production on cheese under modified atmospheres. 
Int. J. Food Microbiol.. 68, 125-133.

23. Tournas, V. (1994). Heat-resistant fungi of importance to the food and beverage industry. Crit. Rev. Microbiol. 20, 243-263.

24. Tournas, V.; Traxler, R.W. (1994). Heat resistance of a Neosartorya fischeri strain isolated from pineapple juice frozen concentrate. J. Food Prot. 57, 814-816.

25. Valík, L.; Piecková, E. (2001). Growth modeling of heat resistant fungi: the effect of water activity. Int. J. Food Microbiol. 63, 11-17.

26. Zwietering, M.H.; Jongenburger, I.; Rombouts, F.M.; Van't Riet, K. (1990). Modeling of bacterial growth curve. Appl. Environ. Microbiol. $56,1875-1881$.

27. Zwietering, M.H.; Koos, J.T.; Hasenack, B.E.; Wit, J.C.; Vant't Riet, K (1991). Modeling of bacterial growth as a function of temperature. Appl. Environ. Microbiol. . 57, 1094-1101. 